\title{
Classification of long-term very long period (VLP) volcanic earthquakes at Whakaari/White Island volcano, New Zealand
}

\author{
Iseul Park ${ }^{1,2^{*}}$, Arthur Jolly ${ }^{2}$, Ivan Lokmer ${ }^{3}$ and Ben Kennedy
}

\begin{abstract}
We have observed very long period earthquakes (VLPs) over the period 2007 to the end of 2019 at Whakaari/White Island volcano, New Zealand. The earthquakes exhibit similitude between waveforms which suggests repeating source locations and processes. VLPs recorded at two permanent stations were detected using waveform semblance and were then classified into two main families (F1 and F2) using a clustering analysis. The two families are characterized by'mirror image' reverse waveform polarity suggesting that they are genetically related, but occur during different evolutionary phases of volcanic activity. F1 events occurred throughout the observation period, while F2 events mainly occurred as swarms that mark the onset of volcanic unrest. A detailed cluster analysis reveals possible sub-families implying slight temporal evolutions within a family. Our results add to our understanding of the volcanic magma-hydrothermal system at Whakaari/White Island indicating that relatively stable VLP sources may be exploited to improve monitoring for future unrest.
\end{abstract}

Keywords: VLP, Earthquake family, Swarm, Volcanic unrest, Clustering analysis

\section{Introduction}

Whakaari/White Island (Fig. 1a) is one of New Zealand's most active volcanoes and has been a frequent tourist destination. Since 2007, this volcano has produced seven hazardous eruptions, and a recent eruption in December 2019 tragically resulted in 21 fatalities. Hence, there is a need for improved monitoring and research of Whakaari/ White Island dynamics (e.g., Chardot et al. 2015). Seismic analysis remains a highly valuable tool for volcano monitoring although recent failures to forecast hydrothermal or phreatic eruptions have highlighted the need for additional research worldwide (Yamaoka et al. 2016). Whakaari/White Island has produced various types of volcanic earthquakes with different frequency contents including very long period (VLP; $f<0.1 \mathrm{~Hz}$ ), long period (LP; $f=0.5-2 \mathrm{~Hz}$ ), high frequency (HF; $f=2-10 \mathrm{~Hz}$ ) and

\footnotetext{
*Correspondence: i.park@gns.cri.nz

1 Department of Geological Sciences, University of Canterbury,

Christchurch 8140, New Zealand

Full list of author information is available at the end of the article
}

volcano tectonic $(f>5 \mathrm{~Hz})$ events (Nishi et al. 1996; Jolly et al. 2017). The long wavelengths of VLP are conducive to source characterization because their waveforms are less impacted by topography and subsurface structural heterogeneity. VLPs have been observed during eruptions at Whakaari/White Island (Caudron et al. 2018; Jolly et al. 2018) as well as many other volcanoes: e.g., Stromboli in 2007 (Giudicepietro et al. 2009), Redoubt in 2009 (Haney et al. 2013), and Merapi in 2010 (Jousset et al. 2013). In contrast, Zuccarello et al. (2013) observed VLP events during degassing without eruptive activity at Mount Etna.

VLP events are often studied using waveform similarity. At Erebus volcano, three VLP families associated with strombolian eruptions were classified based on initial polarity, and waveform and spectral similarity (Mah 2003). Esposito et al. (2008) clustered VLP waveforms according to different eruptive vents of Stromboli volcano. Dawson and Chouet (2014) found that three VLP types are linked to different surficial and subsurface activity at Kilauea volcano ( 7 years). These 

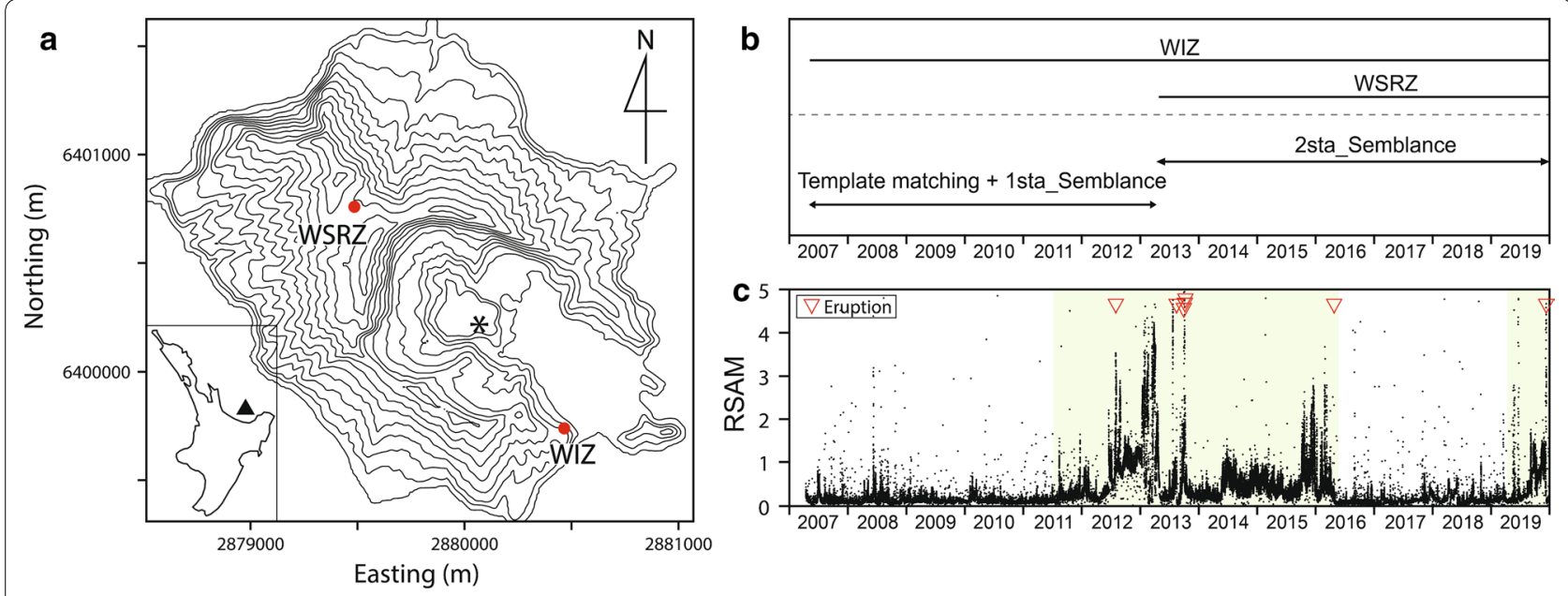

Fig. 1 a Location map of White Island volcano (triangle) including two permanent seismic stations (dots), WIZ and WSRZ, and the active vent (asterisk); $\mathbf{b}$ the station availability and methods used in this study. Note that 2sta and 1sta indicate the use of two stations and one-station analysis, respectively. c One hour sampled RSAM of vertical component data $(\mu \mathrm{m} / \mathrm{s})$ recorded at WIZ station from bandpass-filtered data $(2-5 \mathrm{~Hz})$. The onset times of seven eruptions and unrest phases are marked by reversed triangles (red) and shaded parts (green), respectively

studies revealed stationary sources from several days to years. Relatively long-term VLP activity is documented at Kilauea (Dawson and Chouet 2014) and Popocatepetl (Arciniega-Ceballos et al. 2003) volcanoes, and other volcanoes such as Erebus (Mah 2003; Aster et al. 2008), Etna (Saccorotti et al. 2007), and Stromboli (Marchetti and Ripepe 2005; Esposito et al. 2008) also revealed short- or long-term stable VLP activity. Most VLP studies evoke pressure variations related to gas and magma intrusion (e.g., Arciniega-Ceballos et al. 1999; Aster et al. 2003; Molina et al. 2008; Nakamichi et al. 2009; Dawson et al. 2010; Lyons and Waite 2011; Maeda and Takeo 2011).

Previous VLP studies at Whakaari/White Island have mainly dealt with their source properties. On 19 to 21 August 2011, a swarm of mixed frequency events including VLP, LP, and HF components was recorded on a temporary seismic array (Jolly et al. 2017). The authors reported a depth of $0.8-1.5 \mathrm{~km}$ for VLP, while contemporaneous LP and HF components occurred at shallower depths $(<1 \mathrm{~km})$. They interpreted the coupled events as part of the migration of fluids into the shallower hydrothermal system. Caudron et al. (2018) studied two VLP events recorded during the 2013 eruption episode and found a similar source depth to the 2011 swarm (Jolly et al. 2017). VLP signals were also observed before and during the 2016 eruption sequence, and their source locations of $0.8-1.0 \mathrm{~km}$ depth and mechanisms of volumetric changes were investigated by waveform semblance and source inversion, respectively (Jolly et al. 2018). For all cases, VLP originated beneath the active vent at $\sim 1 \mathrm{~km}$ depth and were inferred to result from fluid migration at the interface between the shallow magmatic conduit and the overlying hydrothermal system.

Although some studies have assessed long-term trends of volcanic activity including volcanic tremor (Chardot et al. 2015), chemical and lake data (Christenson et al. 2017), and seismic ambient noise (Yates et al. 2019), there is generally a lack of research on long-term observation of VLP earthquakes at Whakaari/White Island. As the assessment of long-term volcano hazards becomes increasingly important, it is clear that a rigorous assessment of VLP occurrence and their relation to volcanic activity is required. However, the detection and discrimination of these important event types can be challenging.

In this paper, we observe enduring VLP earthquake families recorded at Whakaari/White Island for the period of 2007-2019. The VLP events are distinguished by using both waveform semblance and a templatematching technique. For the resulting catalogue, we examine their temporal variations and compare them to heightened unrest and eruption occurring during the period 2011-2016 and 2019, in order to assess possible links between VLP activity and eruptions. We find that VLP source excitations are pervasive during periods of both unrest and repose, but that VLP families relate to different periods of quiescence and unrest/eruption. The results have implications for the assessment of unrest at Whakaari/White Island volcano. 


\section{Background at Whakaari/White Island}

GeoNet has operated two permanent stations, WIZ and WSRZ, each consisting of three-component Guralp CMG-3ESP 60-s broadband sensors and 24-bit Quanterra Q330 digitizers which have operated since 20 April 2013; between 2007 and 2013 a single broadband sensor at WIZ was operated (Fig. 1a, b). Prior to this, the WIZ station comprised a short period sensor which was incapable of detecting VLP events (Jolly et al. 2017). In this study, we use the continuous seismic data recorded from 19 April 2007 to 31 December 2019 to identify VLP signals. All seismic records have $100 \mathrm{~Hz}$ sampling frequency.

Whakaari/White Island experienced two unrest episodes, including eruptions, since broadband seismic monitoring was established. The onset of volcanic unrest is defined by integration analysis of a full range of geological and geophysical observations including seismicity, gas discharge and deformation; hence a study of past unrest may provide evidence of potential upcoming unrest (Potter et al. 2015). One of the crucial elements for identifying unrest at Whakaari/White Island is the realtime seismic amplitude measurement (RSAM; Fig. 1c). The RSAM is computed from the RMS amplitude of 1-h sampled velocity data in the frequency range $2-5 \mathrm{~Hz}$ and allows an assessment of volcanic tremor energy (Chardot et al. 2015). The RSAM increased from early 2011 (Christenson et al. 2017), and the onset of the first unrest period was marked in August 2011 at Whakaari/ White Island after integrated analysis with visual observation (Chardot et al. 2015; Edwards et al. 2017). The amplitude rapidly decreased to background levels in May 2016. During the first unrest period in 2011-2016, three eruptive sequences occurred in 2012, 2013 and 2016 containing six distinct eruptions. In early August 2012, the Volcanic Alert Level (VAL) was raised to 2 indicating moderate volcanic unrest due to an increase in tremor and degassing activity. Following the level increased, the volcano erupted ash and blocks, and minor less distinct mud eruptions occurred later in August (Chardot et al. 2015). During the period of January to July 2013, mud and dry ash venting frequently occurred depending on the condition of the crater lake (Jolly et al. 2016; Edwards et al. 2017). The second eruptive episode occurred in August and October 2013 with four short lived eruptions which included steam, mud and explosive activity (Chardot et al. 2015; Caudron et al. 2018). On 27 April 2016, a phreatic eruption was observed (Jolly et al. 2018; Kilgour et al. 2019; Walsh et al. 2019). From April 2019, the RSAM slightly increased, followed by an increasing trend in June. GeoNet raised the VAL to 2 in the middle of June and November 2019. Following the VAL change, the tremor levels increased further and culminated in an explosive eruption on 9 December 2019 at 14:11 NZDT (UTC 01:11).

\section{Detection of VLP volcanic signals}

To identify VLP signals associated with volcanic activity, we applied a three-step process depending on station availability (Fig. 1b). We (1) detected VLP volcanic signals based on waveform semblance using the two-station data recorded 2013-2019 and (2) determined template events using the 2013-2019 semblance triggered signals by a clustering analysis for VLP identification prior to 2013. We then (3) applied a template-matching method over the 2007-2013 period when only one station was recording, followed by the removal of spurious signals. For detailed explanations refer to the following sub-sections. All seismic recordings are bandpass filtered at $0.03-0.1 \mathrm{~Hz}$ to isolate the most energetic part of the recorded VLP signals to be consistent with previous studies (Caudron et al. 2018; Jolly et al. 2017, 2018). This frequency band, however, can be affected by ocean microseism at approximately $0.07 \mathrm{~Hz}$ (Yates 2018).

\section{Triggering VLPs using waveform semblance}

A Whakaari/White Island VLP detection approach was outlined in Jolly et al. (2018) where several hours of preeruption VLPs were identified prior to the April 27, 2016 eruption by application of a moving window grid search for the waveform semblance (Kawakatsu et al. 2000). This approach exploits radial energy propagation among seismograms at the selected VLP passband. The detection algorithm computed the 3-min waveform semblance within a coarse $3 \mathrm{D}$ grid centred on the main vent area in which specific VLP activity may occur. The grid was $2 \times 2 \times 1.5 \mathrm{~km}$ having lateral and vertical spacing of 1 and $0.5 \mathrm{~km}$, respectively. The grid geometry allows discrimination between VLP excitations originating at a range of depths beneath the volcanic vent (coherence from the centre grid elements) and non-volcanic excitations (coherence on margin elements of the grid which relate to teleseismic excitations beyond the volcano) (Jolly et al. 2017). This sparse array algorithm was initially tested against the 2013 and 2016 eruption sequences with various semblance thresholds beneath the vent area regardless of depth to assure that it could successfully capture the target VLP seismicity. After testing, we extended the algorithm to the period April 2013 to December 2019 using the semblance threshold of 0.65 , when two permanent GeoNet stations were operated. Note that the semblance is stable at high signal-to-noise ratio $(\mathrm{SNR}>3)$ in Whakaari/White Island dataset (Jolly et al. 2017). We thus selected VLP events, which have high median SNR of 3-component bandpass-filtered records from both stations, giving 92 events (Fig. 2a and Additional file 1). 
a

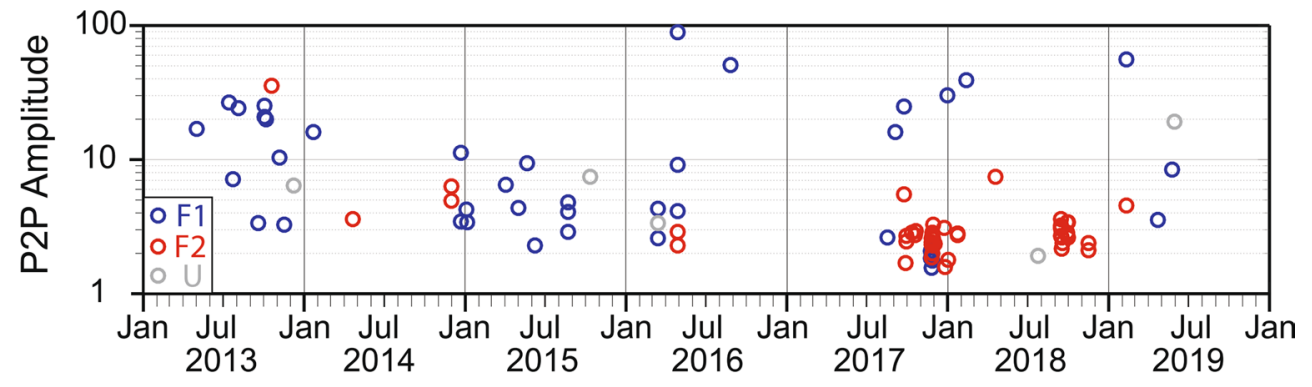

b

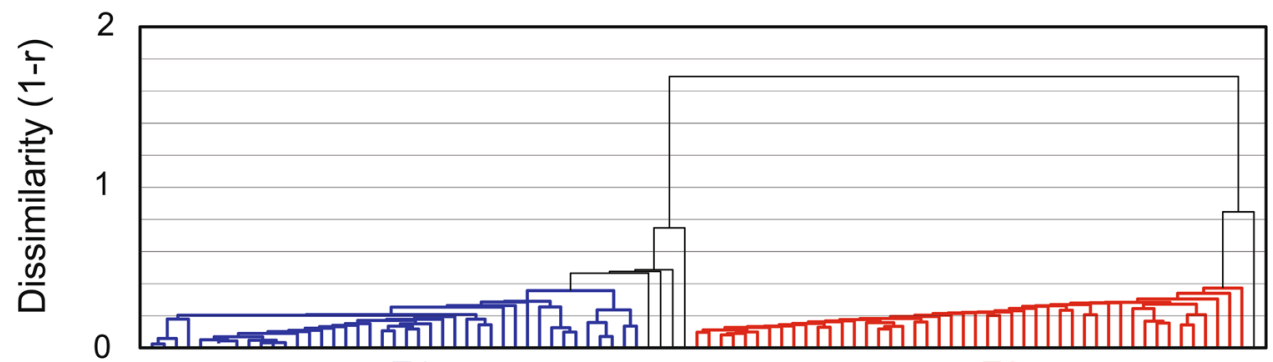

F1

F2

C

F1

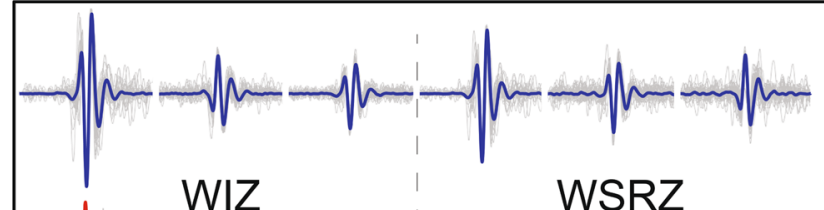

F2
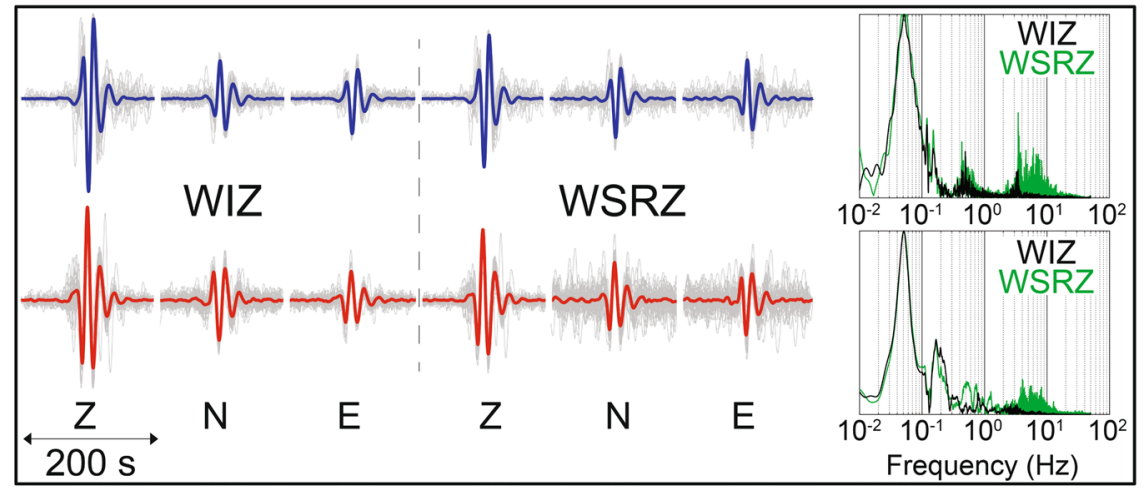

Fig. 2 Triggered VLP signals based on two-station waveform semblance. a Peak-to-peak (P2P) amplitude ( $\mu \mathrm{m} / \mathrm{s}$ ) of VLP families (F1 and F2) and unrelated events ( $U$; gray) determined by $\mathbf{b}$ a cluster tree. The amplitude is computed using the vertical component of WIZ station. This dendrogram is created based on the correlation distance in all pairs of $92 \mathrm{VLP}$ events and its $x$ axis is event index regardless of a time order (can check VLP triggered time and index information in Additional file 1). c Stacked waveforms (thick coloured lines) of individual events (thin gray lines) for the two identified families recorded at WIZ and WSRZ stations. Frequency spectra are computed using each unfiltered example waveform recorded at WIZ (black) and WSRZ (green). All amplitudes are normalized. The stacking procedure is based on actual amplitude, and the stacked events are used as templates (see in "Template-matched VLPs" section)

\section{Determining template events}

The 92 selected events were used to calculate the correlation coefficient $(r)$ between all pairs of 3-component data at both stations. We then completed a hierarchical clustering analysis based on dissimilarities or Pearson correlation distance defined as $1-r$ (Fig. $2 b$ ). The distance ranges from $0(r=1)$ to $2(r=-1)$. For clarity, we use similarity given by $r$ for the rest of the paper. The concept of hierarchical clustering and corresponding algorithms are well documented in Duda and Hart (1973) and Aminzadeh and Chatterjee (1984). In this study, the cluster tree or dendrogram was created using an average linkage algorithm. By considering correlation of multi components, we can determine families, potentially produced by similar sources/processes. In the dendrogram (Fig. 2b), two main clusters (F1 and F2) are determined at a similarity threshold of $r=0.6$, and the remaining signals (U) belong to neither F1 nor F2 clusters possibly due to noise contamination or variations associated with a nonrepeating source. We also confirmed that $U$ is irrelevant to the clusters by a clustering analysis based on the absolute value of correlation coefficient $(1-|r|$; Additional file 2). Several sub-groups from the main clusters can be divided as the threshold increases. However, they are dissimilar to each other at only high correlation threshold, hence the two main families with lower threshold are 
regarded as the most robust grouping. Template events were determined by stacking each family to minimize noise effect (Fig. 2c). VLP signals within each family display similar waveforms event-to-event (Fig. 2c) which may indicate a stable source process (e.g., Chouet 1996; Stephens and Chouet 2001; Green and Neuberg 2006; Petersen et al. 2006; Park et al. 2019), despite the variation in surface activity (Edwards et al. 2017). They also show temporal variations in amplitude implying a source intensity change.

\section{Template-matched VLPs}

The 2-station semblance catalogue only encompasses about half of the 2011-2016 unrest period, hence we sought to develop a method to robustly evaluate the earlier period when only one broadband sensor was available (Fig. 1b). In order to detect VLP events recorded prior to April 2013 at WIZ station, we applied a template-matching method which is based on waveform correlation (e.g., Chouet 1996; Stephens and Chouet 2001; Green and Neuberg 2006; Petersen et al. 2006; Park et al. 2019) between the two stacked waveforms (Fig. 2c) and continuous 3-component data. The optimal correlation threshold was found by applying the method to the seismic recording for the 2013-2019 period containing the triggered semblance events; $91 \%$ of these events were successfully detected by using the correlation threshold of 0.7. The template-matching catalogue for the period 2007 to 2013 contains VLP signals and irrelevant events which may be produced outside of the vent area including local earthquakes and teleseisms (Additional file 3). To exclude unrelated long period events, we applied a single-station semblance filter. Although this approach is inadequate to completely eliminate teleseisms, it contributes by capturing radiational transients from the vent direction. To select an optimum semblance threshold of one-station data, we compared both semblance values derived from twostation data and one-station data, and the consequent single-station VLP catalogue was limited by semblance of $\geq 0.70$. We also restricted the catalogue by the aforementioned SNR condition $(\geq 3)$ and filtered out a small number of extraneous transients from the single-station catalogue using both an empirical SNR filter and visual inspection (Fig. 3). A total of 76 VLP events are selected from 2007-2013 catalogue by template-matching and single-station semblance, and 92 events from 2013-2019 data by semblance of two stations. We then assess both the unrest periods and a long quiescent period using the combined Whakaari/White Island VLP catalogue which consists of 168 events (Fig. 3).

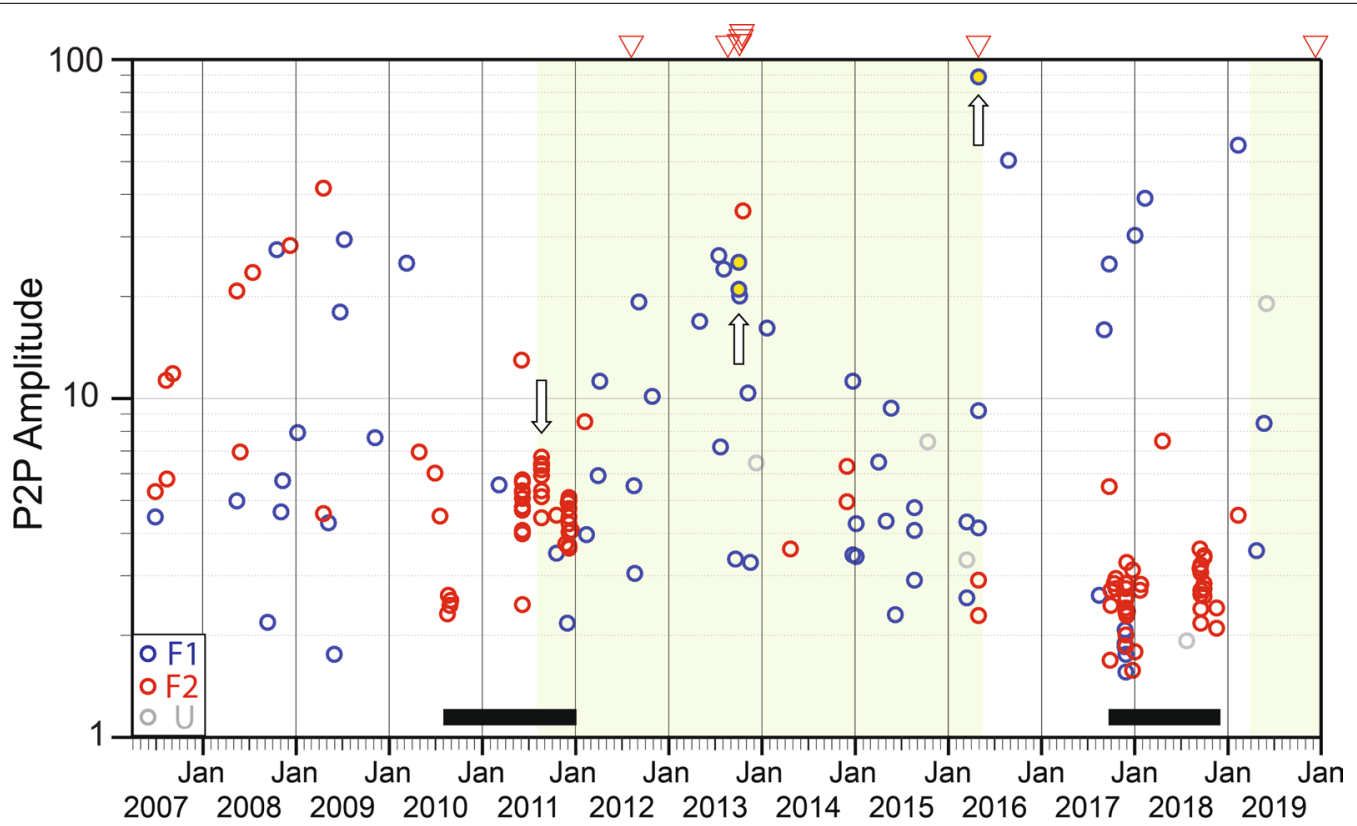

Fig. 3 A combined template-matching catalogue after application to one-station semblance filtering and SNR filters. The yellow filled circles indicate eruptive VLPs. The seven eruptions and swarm periods are denoted by reversed triangles (red) and horizontal bars (black) on the top and bottom of the figure, respectively. Volcanic unrest phases are marked by shaded parts (green), and white arrows indicate VLP events used in previous studies 


\section{Combined VLP catalogue}

A total of 168 VLP pulses are extracted from 2007-2019 seismic data using the template-matching and semblance filters described above (Fig. 3). With the two-station semblance and clustering analysis, we classified triggers into two super-families (F1-F2) based on the waveform similarity. A super-family was defined as a group of similar signals implying analogous source process even with slight variations (Park et al. 2019). The F1 event type represents 64 VLPs, whereas F2 type was more active and included 99 events. The remaining events $(\mathrm{U})$ are not defined as either of the families and may be impacted by noise or may relate to a non-repeating source process. F1 type occurred over the entire observation period. By contrast, about $74 \%$ of F2 family are distributed in swarm activity in 2010-2011 and 2017-2018 (Fig. 3).

The super-families have possible sub-clusters depending on the selected similarity threshold. This can be interpreted in the context of the temporal evolution of volcanic activity. To examine variations in sub-families, we re-conducted the cluster analysis for each family using 3-component data (Fig. 4). Under a similarity threshold of 0.80 , the $\mathrm{F} 1$ family is divided into seven slightly different family types, and their distribution yields temporal variations without meaningful features (Fig. 4a).
In contrast, the F2 family shows systematic variations between the primary swarms and non-swarm sub-clusters (Fig. 4b). Note that this suggests a more stable source process for swarm activity compared to non-swarm events over the observation period. If we choose a higher threshold of 0.85 , one of F1 sub-families (orange circles in Additional file 4) was separated for the first unrest, but has a similar waveform to others which occurred for the repose period. As the correlation threshold increases, the number of clusters also increases, but the waveform characteristics become difficult to distinguish. Due to the potential for noise contamination, caution should be exercised with an interpretation of sub-family occurrence in the case where a higher similarity threshold is applied.

The two super-families show slight waveform evolution within a family group, and their peak-to-peak amplitude varied over the observed time. To check the evolutionary process, we also computed correlation coefficients between individual VLP events and each family stacked waveform as outlined by Park et al. (2019). The results indicate multimodal features implying that the two distinct families occur simultaneously without slow or rapid evolution between different families. Interestingly, a strong negative correlation of -0.97 was observed between stacked waveforms of F1 and F2 events (Fig. 2c),
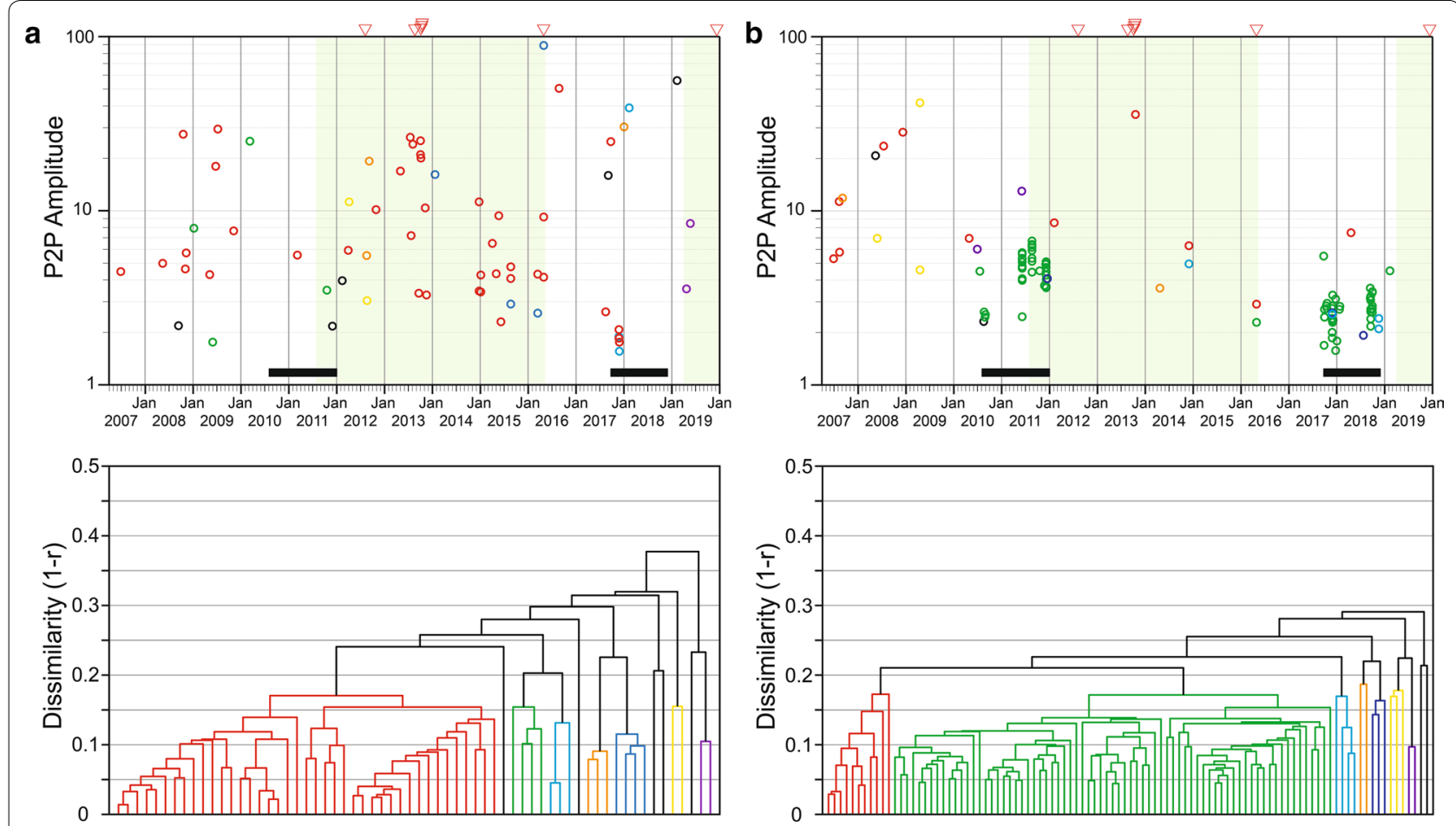

Fig. 4 Temporal variations in sub-families within $\mathbf{a} \mathrm{F} 1$ and $\mathbf{b}$ F2 resulted from correlation threshold of $r=0.80$ in the cluster tree. Note that a range of correlation distance is originally from 0 to 2, and $y$-scale is adjusted. All markers on the figure are the same in Fig. 3. The colours in both peak-to-peak amplitude and cluster tree correspond 
which suggests a 'mirror image' reversed waveform polarity for the two families. We also note that the occurrence of F1 events usually coincided with a dearth of F2 events before 2017 (Fig. 3).

\section{Link between VLP seismicity and unrest}

This analysis revealed two main VLP types during the period of 2007-2019. Regardless of event types, the occurrence of VLP earthquakes suggests ongoing activity in the volcanic edifice since they originate directly beneath the active vent and are interpreted to represent the response to fluid mass transport (Jolly et al. 2017, 2018). To understand long-term VLP activity, we first attempted to compare our observations with previous studies and highlight particular VLP events associated with volcanic unrest at Whakaari/White Island.

We note that the occurrence of VLP swarm activity was observed before the commencement of both unrest periods (Fig. 3). At the beginning of the first unrest, VLPs occurred as the same event type of F2 family and similar amplitude distribution in June, August and December 2011. The August swarm was interpreted to be from gas slug ascent related to the subsequent 2012-2013 eruptions (Jolly et al. 2017). Following the swarm activity, the occurrence of F2 events substantially decreased and F1 events were more prevalent. Although repeating F2 VLP activity decreased, the volcano first erupted on 4 August 2012 followed by a sequence of degassing and dome forming eruption along with the strong volcanic tremor (Chardot et al. 2015).

The first unrest period ended after the April 2016 eruption and weak tremor was observed for more than 1 year. Vigorous VLP activity initiated from late 2017 and consisted of F2 type with a small number of F1 events. Unlike the 2011 activity, higher amplitude F2 swarm again occurred instead of eruptions in the following year. However, a small number of F2 events were also detected in August 2010. We also assessed the occurrence of F2 events having lower amplitude in the template-matching results without the SNR and semblance filters (Additional file 3). Following the 2018 swarm F2 events diminished and the seismic activity evolved into elevated RSAM beginning in 2019. The RSAM unrest was then followed by the eruption on 9 December 2019.

Based on the swarm observations, we note that a VLP swarm composed primarily of F2 family events has preceded two unrest and eruption episodes at Whakaari/ White Island. This observation requires additional example unrest episodes to develop this possible evolutionary pathway at Whakaari/White Island. Additionally, we note that the occurrence of VLP swarms and the onset RSAM is indistinct and the 2017 swarm in particular, did not include an associated increase in RSAM.
In contrast, F1 type events were irregularly observed over the entire period. Although the sub-clusters in the similarity threshold of 0.85 show the difference between repose and unrest event types, it is uncertain whether this represents a source change under our data evaluation conditions. Interestingly, three high-amplitude VLP events from the F1 family (yellow filled circles in Fig. 3), contemporaneously accompany the phreatic eruptions on 3 October 2013 (Caudron et al. 2018) and 27 April 2016 (Jolly et al. 2018). However, because high-amplitude F1 events were also observed during the repose period and the five other eruptions produced other types of volcanic earthquakes, this event type requires additional study and more eruption examples.

Waveforms within a family show modest changes over time, but the changes are too indistinct to resolve features that might relate to changes in source location or mechanism. Their amplitudes also varied over time which might imply change in source intensity. Consequently, we can assume that a family is generated by a similar source process and potential location. According to previous studies, both F1 and F2 families probably related to the upward migration of gas slugs (Jolly et al. 2017, 2018; Caudron et al. 2018). However, Jolly et al. (2018) noted strong static deformation during the 2016 eruption. They suggested that this deformation could have resulted from magmatic injection into the overlying magma carapace. Hence, large F1 events might include near-conduit magma injection. Gas-related VLP mechanisms are commonly invoked at volcanoes. For example, at Stromboli volcano, Ripepe et al. (2005) interpreted a close link between rates of gas and VLP rate during the 2003 eruption. Kazahaya et al. (2011) also examined that $\mathrm{SO}_{2}$ flux was proportional to moment of isolated VLP pulses recorded for a day during gas bursts at Mount Asama. In such short-term analysis, VLP activity is likely to display a positive relationship with gas measurements. However, a complex interplay within a volcano conduit and its overlying crater lake, may lead to inconsistent phenomena leading to ambiguous interpretation of the long-term data. In a conceptual model of Whakaari/ White Island (Cole et al. 2000; Christenson et al. 2017; Jolly et al. 2017), the volcano can be described as a complex vent system in elastic altered rock that is brittlely fragmented by fumarolic pathways with more ductile rock where pressure and porosity allow (Heap et al. 2015). Due to this complicated system, a study on a possible link between surface observations, other monitoring and VLP activity requires additional assessment that is beyond the scope of this study.

The long-term stability of VLP families, at $\sim 1 \mathrm{~km}$ depth, implies a stable and non-destructive source process regardless of eruptive activity. The 
aforementioned small-scale deformations for VLP are noted to produce modelled volume changes larger than $10^{4} \mathrm{~m}^{3}$ (Jolly et al. 2018). The long-term stability of the source process implies that the subsurface plumbing system at the VLP source depth is not modified by explosive activity or the large volumes involved with individual events. Indeed, the observations may reflect the limited range of persistent fluid flux from the underlying magma system and into the shallow hydrothermal system that may be persistent and stable over decades.

It is additionally noted that the opposite polarity for the two primary sources might imply a change in the volumetric or slip direction within the excited source. This change is seen in both vertical and lateral seismometer components (Fig. 2c). Hence, the reverse polarity is robustly observed. The two event types in this study were previously modelled by Jolly et al. (2018; F1 family type) and Jolly et al. (2017; F2 family type). The prior modelling suggests that the mirror image source process relates to an excitation of the same oriented crack but having the opposite sense of slip and volumetric change through time. Future modelling of these events will focus on the nature of inflation/deflation (feed/release) modes to understand plausible source mechanisms.

Although slight waveform evolutions, amplitude variations and the number of events were recognized within a family which might be due to volcanic activity, no distinct new family types are seen over the observation period.

From the above sequence, we highlight three key observations: (1) VLPs show remarkably distinct stable repeating characteristics with little evolution over a 12-year study period; (2) swarms composed of F2 event type were observed before the commencement of both unrest periods, and (3) the 2013 and 2016 eruptions produced F1-type events having high amplitude. F1 events, however, were prevalent over the entire observation time, and an assessment of such features requires further analysis and more eruption cases.

Eruptive activity at Whakaari/White Island is usually observed with an increase in occurrence of volcanic tremor which can be detected by the increasing RSAM trend (e.g., Chardot et al. 2015). Unlike RSAM observation, most VLP events have no clear increase in event size before an eruption (Additional file 5). Whilst a rigorous statistical assessment cannot be completed given the infrequent nature of eruptive activity at Whakaari/ White Island, the observations of the two super-families might be useful for future monitoring assessments at this volcano.

\section{Conclusions}

This study provides the first attempt of the comprehensive detection and analysis of long-term VLP earthquakes at Whakaari/White Island. We have detected and discriminated long-term VLP earthquakes at the volcano using template-matching and waveform semblance methods. We note that the volcano produced two distinct types of VLP families which occur throughout the progression from repose to build-up and unrest including eruptions. The occurrence of these distinct event types is stable over the 12 years and implies a relatively stationary source and mechanism throughout this time. We emphasize that VLP swarms of type F2 appear to relate closely to the onset of volcanic unrest.

We propose that automatic detection and classification of these event types would contribute to improved volcano monitoring of unrest at Whakaari/White Island. In addition, we expect that the detection methods introduced in this study may be effective for sparse stations monitoring for VLP activity at volcanoes worldwide.

Although beyond the scope of this study, interesting swarm observation and the waveform polarity switch might indicate changing source locations and processes which relate to the evolution of subsurface conditions during periods of repose, build-up, unrest and eruptions. Further work may include wider data observations such as InSAR/GPS measurements, gas discharge and lake level changes. Future monitoring efforts should emphasize the collection of higher density observation of such data. These data together with new dense observations of the VLP source will improve our understanding of Whakaari/White Island volcanic system.

\section{Supplementary information}

Supplementary information accompanies this paper at https://doi. org/10.1186/s40623-020-01224-z.

Additional file 1. A list of triggered time (UTC: dd-mm-yyyy hh:mm:ss), peak-to-peak (P2P) amplitude ( $\mu \mathrm{m} / \mathrm{s})$, event order in the cluster tree, and family index (F1, F2 and U) for VLPs recorded at WIZ and WSRZ stations. This table supports Fig. 2.

Additional file 2. A dendrogram based on the absolute value of correlation coefficient. Two families (F1 and F2) belong to a cluster (orange lines) except for one low SNR waveform, and all $U$ events denote black lines.

Additional file 3. Template matching results (gray dots) without semblance and SNR filtering. This catalogue includes two families (F1 and F2) as well as teleseismic data and lower SNR events. The vertical axis is peakto-peak (P2P) amplitude ( $\mu \mathrm{m} / \mathrm{s}$ ) computed using the vertical component of WIZ station

Additional file 4. Peak-to-peak amplitude and cluster tree of $\mathbf{a} \mathrm{F} 1$ and $\mathbf{b}$ F2 sub-families resulted from threshold of $r=0.85$. The seven eruptions, unrest and swarm periods are denoted by reversed triangles (red), shaded areas (green) and horizontal bars (black), respectively. The colours in both top and bottom plots correspond.

Additional file 5. Cumulative amplitude of F1 (blue) and F2 (red). The seven eruptions are denoted by reversed triangles (red). Time map of two 
VLP families (F1 and F2). Axes indicate the time intervals between each VLP and its preceding ( $x$ axis) and subsequent (y axis) events. Swarm and intermittent VLPS are separately clustered.

\section{Abbreviation}

VLP: Very long period.

\section{Acknowledgements}

The seismic data in this study were collected from the GeoNet (FDSN; https ://www.geonet.org.nz/data/tools/FDSN). BK would like to acknowledge "Quantifying exposure to specific and multiple volcanic hazards" program of the New Zealand Natural Hazards Research Platform (NHRP). AJ was funded by the Ministry of Business, Innovation and Employment (MBIE) Strategic Science Investment Fund (SSIF) and the Resilience to Nature's Challenges (RNC2) volcano research program. Reviews by Steve Sherburn (GNS Science) and Gill Jolly (GNS Science) improved an early version of the manuscript. We acknowledge the Editor Mare Yamamoto and two anonymous reviewers for their constructive comments that improved the later manuscript.

\section{Authors' contributions}

All authors supported the writing. All authors read and approved the final manuscript.

\section{Funding}

BK would like to acknowledge "Quantifying exposure to specific and multiple volcanic hazards" program of the New Zealand Natural Hazards Research Platform (NHRP). AJ was funded by the Ministry of Business, Innovation and Employment (MBIE) Strategic Science Investment Fund (SSIF) and the Resilience to Nature's Challenges (RNC2) volcano research program.

\section{Availability of data and materials}

The seismic data in this study were collected from the GeoNet (FDSN; https:// www.geonet.org.nz/data/tools/FDSN).

\section{Ethics approval and consent to participate}

Not applicable.

\section{Consent for publication}

Not applicable.

\section{Competing interests}

Arthur Jolly is a member of the editorial board and has been blinded from the review process. The other authors declare that they have no competing interests.

\section{Author details}

${ }^{1}$ Department of Geological Sciences, University of Canterbury, Christchurch 8140, New Zealand. ${ }^{2}$ GNS Science, 1 Fairway Drive, Avalon, Lower Hutt 5010, New Zealand. ${ }^{3}$ School of Earth Sciences, University College Dublin, Belfield, Dublin 4, Ireland.

Received: 9 April 2020 Accepted: 29 June 2020

Published online: 06 July 2020

\section{References}

Aminzadeh F, Chatterjee S (1984) Applications of clustering in exploration seismology. Geoexploration 23:147-159. https://doi.org/10.1016/00167142(84)90028-0

Arciniega-Ceballos A, Chouet BA, Dawson P (1999) Very long-period signals associated with Vulcanian Explosions at PopocatepetI Volcano, Mexico. Geophys Res Lett 26(19):3013-3016. https://doi.org/10.1029/1999GL0053 90

Arciniega-Ceballos A, Chouet BA, Dawson P (2003) Long-period events and tremor at Popocatepetl volcano (1994-2000) and their broadband characteristics. Bull Volcanol 65:124-135. https://doi.org/10.1007/s0044 5-002-0248-8
Aster R, Mah S, Kyle P, McIntosh W, Dunbar N, Johnson J, Ruiz M, McNamara S (2003) Very long period oscillations of Mount Erebus Volcano. J Geophys Res B Solid Earth 108(B11):2522. https://doi.org/10.1029/2002JB002101

Aster R, Zandomeneghi D, Mah S, McNamara S, Henderson DB, Knox H, Jones $\mathrm{K}$ (2008) Moment tensor inversion of very long period seismic signals from Strombolian eruptions of Erebus Volcano. J Volcanol Geotherm Res 177:635-647. https://doi.org/10.1016/j.jvolgeores.2008.08.013

Caudron C, Taisne B, Neuberg J, Jolly AD, Christenson B, Lecocq T, Suparjan, Syahbana D, Suantika G (2018) Anatomy of phreatic eruptions. Earth Planets Space 70:168. https://doi.org/10.1186/s40623-018-0938-x

Chardot L, Jolly AD, Kennedy BM, Fournier N, Sherburn S (2015) Using volcanic tremor for eruption forecasting at White Island volcano (Whakaari), New Zealand. J Volcanol Geotherm Res 302:11-23. https://doi.org/10.1016/j. jvolgeores.2015.06.001

Chouet BA (1996) Long-period volcano seismicity: its source and use in eruption forecasting. Nature 380:309-316. https://doi.org/10.1038/380309a0

Christenson BW, White S, Britten K, Scott BJ (2017) Hydrological evolution and chemical structure of a hyper-acidic spring-lake system on Whakaari/ White Island, NZ. J Volcanol Geotherm Res 346:180-211. https://doi. org/10.1016/j.jvolgeores.2017.06.017

Cole JW, Thordarson T, Burt RM (2000) Magma origin and evolution of White Island (Whakaari) volcano, Bay of plenty, New Zealand. J Petrol 41(6):867895. https://doi.org/10.1093/petrology/41.6.867

Dawson P, Chouet B (2014) Characterization of very-long-period seismicity accompanying summit activity at Kilauea Volcano, Hawaii: 2007-2013. J Volcanol Geotherm Res 278-279:59-85. https://doi.org/10.1016/j.jvolg eores.2014.04.010

Dawson PB, Benítez MC, Chouet BA, Wilson D, Okubo PG (2010) Monitoring very-long-period seismicity at Kilauea Volcano, Hawaii. Geophys Res Lett 37:L18306. https://doi.org/10.1029/2010GL044418

Duda RO, Hart P (1973) Pattern classification and scene analysis. Wiley, New York

Edwards MJ, Kennedy BM, Jolly AD, Scheu B, Jousset P (2017) Evolution of a small hydrothermal eruption episode through a mud pool of varying depth and rheology, White Island, NZ. Bull Volcanol 79:16. https://doi. org/10.1007/s00445-017-1100-5

Esposito AM, Giudicepietro F, D'Auria L, Scarpetta S, Martini MG, Coltelli M, Marinaro M (2008) Unsupervised neural analysis of very-long-period events at Stromboli Volcano using the self-organizing maps. Bull Seismol Soc Am 98(5):2449-2459. https://doi.org/10.1785/0120070110

Giudicepietro F, D'Auria L, Martini M, Caputo T, Peluso R, De Cesare W, Orazi M, Scarpato G (2009) Changes in the VLP seismic source during the 2007 Stromboli eruption. J Volcanol Geotherm Res 182:162-171. https://doi. org/10.1016/j.jvolgeores.2008.11.008

Green DN, Neuberg J (2006) Waveform classification of volcanic low-frequency earthquakes swarms and its implication at Soufrière Hills Volcano, Montserrat. J Volcanol Geotherm Res 153(1-2):51-63. https://doi.org/10.1016/j. jvolgeores.2005.08.003

Haney MM, Chouet BA, Dawson PB, Power JA (2013) Source characterization for an explosion during the 2009 eruption of Redoubt Volcano from verylong-period seismic waves. J Volcanol Geotherm Res 259:77-88. https:// doi.org/10.1016/j.jvolgeores.2012.04.018

Heap MJ, Kennedy BM, Pernin N, Jacquemard L, Baud P, Farquharson JI, Scheu B, Lavallée Y, Albert Gilg H, Letham-Brake M, Mayer K, Jolly AD, Reuschlé T, Dingwell DB (2015) Mechanical behaviour and failure modes in the Whakaari (White Island volcano) hydrothermal system, New Zealand. J Volcanol Geotherm Res 295:26-42. https://doi.org/10.1016/j.jvolgeores 2015.02.012

Jolly A, Kennedy B, Edwards M, Jousset P, Scheu B (2016) Infrasound tremor from bubble burst eruptions in the viscous shallow crater lake of White Island, New Zealand, and its implications for interpreting volcanic source processes. J Volcanol Geotherm Res 327:585-603. https://doi. org/10.1016/j.jvolgeores.2016.08.010

Jolly AD, Lokmer I, Thun J, Salichon J, Fry B, Chardot L (2017) Insights into fluid transport mechanisms at White island from analysis for coupled very long-period (VLP), long-period (LP) and high-frequency (HF) earthquakes. J Volcanol Geotherm Res 343:75-94. https://doi.org/10.1016/j.jvolgeores 2017.06.006

Jolly A, Lokmer I, Christenson B, Thun J (2018) Relating gas ascent to eruption triggering for the April 27, 2016, White Island (Whakaari), New Zealand 
eruption sequence. Earth Planets Space 70:177. https://doi.org/10.1186/ s40623-018-0948-8

Jousset P, Budi-Santoso A, Jolly AD, Boichu M, Surono, Dwiyono S, Sumarti S, Hidayati S, Thierry P (2013) Signs of magma ascent in LP and VLP seismic events and link to degassing: an example from the 2010 explosive eruption at Merapi volcano, Indonesia. J Volcanol Geotherm Res 261:171-192. https://doi.org/10.1016/j.jvolgeores.2013.03.014

Kawakatsu H, Kaneshima S, Matsubayashi H, Ohminato T, Sudo Y, Tsutsui T, Uhira K, Yamasato H, Ito H, Legrand D (2000) Aso94: Aso seismic observation with broadband instruments. J Volcanol Geotherm Res 101:129-154. https://doi.org/10.1016/S0377-0273(00)00166-9

Kazahaya R, Mori T, Takeo M, Ohminato T, Urabe T, Maeda Y (2011) Relation between single very-long-period pulses and volcanic gas emissions at Mt. Asama. Geophys Res Lett, Japan. https://doi.org/10.1029/2011GL0475 55

Kilgour G, Gates S, Kennedy B, Farquhar A, McSporran A, Asher C (2019) Phreatic eruption dynamics derived from deposit analysis: a case study from a small, phreatic eruption from Whakāri/White Island, New Zealand. Earth Planets Space 71:36. https://doi.org/10.1186/s40623-019-1008-8

Lyons JJ, Waite GP (2011) Dynamics of explosive volcanism at Fuego volcano imaged with very long period seismicity. J Geophys Res 116:B09303. https://doi.org/10.1029/2011JB008521

Maeda Y, Takeo M (2011) Very-long-period pulses at Asama volcano, central Japan, inferred from dense seismic observations. Geophys J Int 185:265282. https://doi.org/10.1111/j.1365-246X.2011.04938.x

Mah S (2003) Discrimination of Strombolian eruption types using very long period (VLP) seismic signals and video observations at Mount Erebus, Antarctica, M.S. Independent Study, New Mexico Institute of Mining and Technology

Marchetti E, Ripepe M (2005) Stability of the seismic source during effusive and explosive activity at Stromboli Volcano. Geophys Res Lett. https://doi. org/10.1029/2004gl021406

Molina I, Kumagai H, García-Aristizábal A, Nakano M, Mothes P (2008) Source process of very-long-period events accompanying long-period signals at Cotopaxi Volcano, Ecuador. J Volcanol Geotherm Res 176:119-133. https ://doi.org/10.1016/j.jvolgeores.2007.07.019

Nakamichi H, Kumagai H, Nakano M, Okubo M, Kimata F, Ito Y, Obara K (2009) Source mechanism of a very-long-period event at Mt. Ontake, central Japan: response of a hydrothermal system to magma intrusion beneath the summit. J Volcanol Geotherm Res 187(3-4):167-177. https://doi. org/10.1016/j.jvolgeores.2009.09.006

Nishi Y, Sherburn S, Scott BJ, Sugihara M (1996) High-frequency earthquakes at White Island volcano, New Zealand: insights into the shallow structure of a volcano-hydrothermal system. J Volcanol Geotherm Res 72:183-197. https://doi.org/10.1016/0377-0273(96)00005-4

Park I, Jolly A, Kim KY, Kennedy B (2019) Temporal variations of repeating low frequency volcanic earthquakes at Ngauruhoe Volcano, New Zealand. J
Volcanol Geotherm Res 373:108-119. https://doi.org/10.1016/j.jvolgeores 2019.01.024

Petersen T, Caplan-Auerbach J, McNutt SR (2006) Sustained long-period seismicity at Shishaldin Volcano, Alaska. J Volcanol Geotherm Res 151(4):365381. https://doi.org/10.1016/j.jvolgeores.2005.09.003

Potter SH, Scott BJ, Jolly GE, Neall VE, Johnston DM (2015) Introducing the Volcanic Unrest Index (VUI): a tool to quantify and communicate the intensity of volcanic unrest. Bull Volcanol 77:77. https://doi.org/10.1007/ s00445-015-0957-4

Ripepe M, Marchetti E, Ulivieri G, Harris A, Dehn J, Burton M, Caltabiano T, Salerno G (2005) Effusive to explosive transition during the 2003 eruption of Stromboli volcano. Geology 33(5):341-344. https://doi.org/10.1130/ G21173.1

Saccorotti G, Lokmer I, Bean CJ, Di Grazia G, Patanè D (2007) Analysis of sustained long-period activity at Etna Volcano, Italy. J Volcanol Geotherm Res 160:340-354. https://doi.org/10.1016/j.jvolgeores.2006.10.008

Stephens CD, Chouet BA (2001) Evolution of the December 14, 1989 precursory long-period event swarm at Redoubt Volcano, Alaska. J Volcanol Geotherm Res 109(1-3):133-148. https://doi.org/10.1016/50377 -0273(00)00308-5

Walsh B, Procter J, Lokmer I, Thun J, Hurst T, Christenson B, Jolly A (2019) Geophysical examination of the 27 April 2016 Whakaari/White Island, New Zealand, eruption and its implications for vent physiognomies and eruptive dynamics. Earth Planets Space 71:25. https://doi.org/10.1186/ s40623-019-1003-0

Yamaoka K, Geshi N, Hashimoto T, Ingebritsen SE, Oikawa T (2016) Special issue "The phreatic eruption of Mt. Ontake volcano in 2014". Earth Planets Space 68:175. https://doi.org/10.1186/s40623-016-0548-4

Yates AS (2018) Seismic velocity changes at White Island volcano from ambient noise interferometry (Master's thesis). Victoria University of Wellington, Wellington

Yates AS, Savage MK, Jolly AD, Caudron C, Hamling IJ (2019) Volcanic, coseismic, and seasonal changes detected at White Island (Whakaari) volcano, New Zealand, using seismic ambient noise. Geophys Res Lett 46:99-108. https://doi.org/10.1029/2018GL080580

Zuccarello L, Burton MR, Saccorotti G, Bean CJ, Patanè D (2013) The coupling between very long period seismic events, volcanic tremor, and degassing rates at Mount Etna volcano. J Geophys Res 118:4910-4921. https://doi. org/10.1002/jgrb.50363

\section{Publisher's Note}

Springer Nature remains neutral with regard to jurisdictional claims in published maps and institutional affiliations.

\section{Submit your manuscript to a SpringerOpen ${ }^{\circ}$ journal and benefit from:}

- Convenient online submission

- Rigorous peer review

- Open access: articles freely available online

- High visibility within the field

- Retaining the copyright to your article

Submit your next manuscript at $\boldsymbol{\nabla}$ springeropen.com 